\title{
Considerações sobre o uso da videoconferência como elemento viabilizador de EAD em um ambiente multiponto: o caso da Petrobras
}

\section{Considerations about the videoconference use as multipoint support for distance learning environments: a case study at Petrobras}

\author{
Lauro Brito de Almeida* \\ Cláudio Parisi** \\ Mariano Stamato*** $^{* *}$
}

\begin{abstract}
RESUMO
As rápidas e constantes alterações havidas no meio ambiente têm impactado a todos. Uma das consequiências é que os atores são impelidos a buscar maneiras de se adaptarem. Tal quadro tem conduzido as empresas e pessoas a adotarem uma nova postura, sob o risco de, ao não fazê-la, terem suas atividades descontinuadas. A Petrobras, ao longo de sua existência e dadas as suas peculiaridades, tem promovido o desenvolvimento de seus colaboradores patrocinando treinamento ou cursos formais em nível de graduação, pós-graduação; estes, nas suas modalidades stricuto sensu e lato sensu. O caso em questão, objeto deste paper aborda a realização de um MBA - Controller, sob coordenação da Universidade Corporativa no
\end{abstract}

* Prof. Doutor do Decont - Departamento de Contabilidade/sCSA da Universidade Federal do Paraná. E-mail: gbrito@uol.com.br / brito@sociais.ufpr.br

** Prof. Doutor da Fundação Escola de Comércio Álvares Penteado - FECAP. E-mail: claudio@turnpike.com.br

**** Gerente do Planejamento e Orçamento do Desempenho Empresarial da Petrobras. Email: stamato@petrobras.com.br 
qual a mídia videoconferência tem papel de destaque na viabilização do curso no formato semi-presencial.

Palavras-chave: controladoria, EAD, semi-presencial, videoconferência, Universidade Corporativa.

\begin{abstract}
The fast and constant changes in the environment has impacted everybody. The one of the consequences is that the actors are impelled to find way to adapt them to this. This scenario has guided the companies and people to adopt a new behaviour, with the risk of, if not doing it, to have their activities discontinued. The Petrobras during its existence and its peculiarity has promoted the development of its employees, sponsoring trainning or formal course as graduation and pos graduation, this last in stricto sensu and lato sensu level. The case in question, object to this paper approaches the MBA -Controller realization, under the Corporate University coordination wich the midia videoconference has prominence in the viabilization of the semi-presential course.

Key-words: controller, EAD, semi-presential, Corporate University, videoconference.
\end{abstract}

\title{
Introdução
}

De uma maneira geral, as rápidas e constantes alterações havidas no meio ambiente têm impactado a todos. Uma das consequiências é que os atores são impelidos a buscar maneiras de se adaptarem, sobreviverem; se possível, com crescimento e desenvolvimento. Tal quadro tem conduzido o conjunto de atores - empresas e pessoas - a adotarem uma nova postura, sob o risco de, ao não assumi-la, terem suas atividades descontinuadas.

Nos dias de hoje, a regra geral é de as organizações serem adaptativas e/ ou organizações que aprendem. Organizações, são, antes de mais nada, uma reunião de pessoas, de talentos. A adaptação contínua às alterações de "humor" do meio ambiente por parte das organizações, que possibilite não só sobreviver, mas principalmente implementar um processo de crescimento e desenvolvimento, depende fundamentalmente do seu sistema social - pessoas - e estar, além de outras variáveis, capacitadas. 
Capacitação é um processo que depende, em linhas gerais, de duas variáveis: a) disposição, vontade do aprendente e b) acesso e aquisição de conhecimento. A premissa básica é a existência de disposição por parte do aprendente, restando, portanto, viabilizar/concretizar o acesso e aquisição ao conhecimento.

$\mathrm{O}$ acesso e aquisição do conhecimento podem ocorrer de duas maneiras, igualmente clássicas: a) autodidata e b) com a interveniência de uma Instituição de Ensino (IE). Nossa abordagem envolve o acesso e aquisição de conhecimento por meio de uma interação com uma Instituição de Ensino Superior (IES) e ocorre num contexto no qual a organização assume a responsabilidade de viabilizar e concretizar o acesso, cabendo a ela portanto a assunção dos encargos dos programas educacionais e custeio dos alunos.

O objetivo deste artigo é o relato e reflexão sobre a experiência vivida ${ }^{1}$ em um projeto de ensino de pós graduação lato sensu - pioneiro no âmbito dos cursos oferecidos no Programa de Educação Continuada da FIPECAFI/FEA/ USP - a um grupo de alunos geograficamente dispersos, em um curso formatado no modelo semi-presencial. O meio técnico viabilizador de um curso deste tipo - longa duração - é a mídia videoconferência e o curso em questão é o MBA Controller.

\section{Conhecimento, ensino-aprendizagem e controladoria: algumas con- siderações}

Nestes tempos de pós-modernidade e globalização muitos desafios são impostos aos atores sociais. O enfrentamento desses desafios implica na ocorrência de conseqüências, entre as muitas destacamos a intensificação da necessidade de as pessoas buscarem constantemente novos conhecimentos, sob pena de ao não fazê-lo estarem desatualizadas e, portanto, excluídas, com suas possibilidades profissionais cada vez mais reduzidas para permanecerem competitivas no mercado de trabalho.

Desencadeia-se, então, uma busca por conhecimentos como parte de um processo contínuo de maior capacitação profissional - independente do tipo de curso: treinamento, especialização, MBA's.

$1 \mathrm{O}$ prof. Lauro Brito de Almeida, co-autor deste artigo, na época era integrante da equipe de Coordenadores do Curso por parte da FIPECAFI/FEA/USP. 
E o que é conhecimento? CARBONEL (2002, p. 51) o define como

...um conjunto de informações, conceitos, princípios, crenças, valores, símbolos, rituais, linguagens, opiniões, argumentações, habilidades de índole diversa e outros componentes que estão mais ou menos interconectados e atados como os fios de uma rede.

A construção do conhecimento não é simples. É, conforme CARBONEL (2002, p. 51), um processo

...extraordinariamente complexo e multidimensional, assenta-se em três grandes pilares: o da informação, que gera conhecimento relevante; o da explicação, que facilita a compreensão do porquê das coisas; e o da apropriação subjetiva, que contribui para a formação de um critério de opinião pessoal.

Os avanços tecnológicos, em especial na tecnologia de informação, têm possibilitado de forma ímpar a disseminação acelerada da informação. Ocorre, então, um processo contínuo de aquisição de informação, distribuição e conversão em conhecimento, em especial num momento em que informação e conhecimento têm seus ciclos de renovação diminuída e acelerada.

\section{Controladoria: um ramo do conhecimento}

Usualmente Controladoria tem um significado para o público em geral, mesmo àqueles ligados a atividade, de somente ser um departamento ou equivalente, de acordo com uma dada estrutura organizacional. Associamse a ela também, uma visão equivocada de poder controlar/policiar os destinos de uma organização, em especial àquelas voltadas para fins lucrativos. 
O nosso entendimento sobre Controladoria exclui o aspecto de controlar/policiar e adota uma visão abrangente, vista sob duas vertentes. A primeira, enquanto uma unidade administrativa; a segunda, pertinente aos nossos propósitos,

...enquanto ramo do conhecimento e apoiada na Teoria da Contabilidade e uma visão multidisciplinar, é responsável pelo estabelecimento das bases teóricas necessárias para a modelagem, construção e manutenção de Sistemas de Informações e Modelo de Gestão Econômica, que supram adequadamente as necessidades informativas dos Gestores e os induzam durante o processo de gestão, quando requerido, a tomarem decisões ótimas. (ALMEIDA; PARISI e PEREIRA. In: CATELLI, 2001, p. 370)

Nestes tempos de meio ambiente dinâmico e mutante, é um fator-chave o entendimento dos reflexos decorrentes do "...novo status da informação como um ativo e recurso para o desenvolvimento organizacional e vantagem competitiva" (HARE, 2000). A capacitação dos profissionais para não só utilizar, mas principalmente gerenciar a informação, requer - de maneira contínua - a busca, aquisição, acumulação e gerenciamento do conhecimento, independente de sua área de atuação e formação. Ao agirem assim, seja por conta própria ou patrocinados pelas organizações a que estão ligados, estarão estes profissionais em posição de contribuir no delineamento e implementação das estratégias empresarias, como também adquirindo as competências necessárias para realizarem as suas aspirações profissionais.

Suportado nessa visão, o ensino da Controladoria supre cobrir uma lacuna e ao mesmo tempo atender a uma demanda por conhecimentos num ramo específico e, no entanto, de interação multidisciplinar a profissionais de variadas formações quanto a graduação universitária. A multidisciplinaridade verificada no ensino e pesquisa em Controladoria abrange um leque de disciplinas, tais como: Contabilidade, Economia, Sociologia, Matemática Financeira, Estatística, Engenharia de Produção, Psicologia, Teoria das Finanças, Recursos Humanos, Marketing, entre outras.

No contexto, o ensino da Controladoria ocorre num momento em que se torna cada vez mais intenso o debate em torno da mudança de foco do modo clássico de ensino-aprendizagem. Questiona-se a eficácia do modelo "professor discursando e o aluno passivo". O foco é aprender a aprender, em que o papel do professor é mais o de ser um facilitador, um indutor. Vivenciamos 
uma ocasião desafiadora e rica para professores, alunos e demais envolvidos, exigindo reflexão de todos os que conduzam a concepção e construção de modelos flexíveis de ensinar e aprender ante as novas tecnologias de informação postas como instrumentos no EAD, em específico a videoconferência.

\section{O caso Petrobras}

O caso refere-se a uma empresa brasileira que optou por assumir a responsabilidade no processo contínuo de aperfeiçoamento de seus talentos. A área de atuação dos funcionários é a Controladoria, envolvendo as atividades de avaliação de desempenho empresarial, planejamento e controle, orçamento empresarial, custos, contabilidade societária e contabilidade internacional, e o programa educacional é de pós-graduação lato sensu, que vem sendo desenvolvido com sucesso pela FIPECAFI - Fundação Instituto de Pesquisas Contábeis, Atuariais e Financeiras, órgão de apoio ao Departamento de Contabilidade e Atuaria da Faculdade de Economia, Administração e Contabilidade (FEA) da Universidade de São Paulo, na modalidade presencial.

A organização, objeto do caso, é a Petróleo Brasileiro S A - Petrobras. A Petrobras desempenha um papel - além de importante - estratégico na economia brasileira e, conseqüentemente, para a sociedade. As mudanças pelas quais está passando nestes tempos de quebra de barreiras, de liberação de mercados, de privatização, reforça o entendimento que - a despeito da amplitude do termo - a gestão empresarial também é um diferencial de competitividade e que o desafio é contribuir para o processo de capacitação e desenvolvimento de seus talentos, num contexto de dispersão geográfica enquanto locus físico de atuação profissional de seus colaboradores.

\section{A empresa}

A Petrobras é uma empresa que se confunde com muitos aspectos da vida do brasileiro. A sua criação decorre, na época, de uma longa campanha 
popular e insere-se num ciclo histórico no qual se tentou montar as bases industriais brasileiras por meio da criação de estatais nas áreas de siderurgia, metalurgia e petróleo (LUCCHESI, 1998). Por força da especificidade e singularidade de sua atuação, a Petrobras desenvolveu, ao longo deste quase meio século, uma sólida cultura e longa tradição na formação educacional de seus talentos.

A Petrobras é uma sociedade anônima de capital aberto, criada pela lei 2.004 (3/10/1953) e instalada em 10/05/1954. A missão, quando da sua criação e instalação, era a de suprir o mercado interno com petróleo e seus derivados, fosse pela produção nacional, fosse pela importação (LUCCHESI, 1998).

Decorridos 48 anos de sua criação, a Petrobras ocupa hoje a posição de 13. ${ }^{a}$ maior companhia de petróleo no mundo, posição significativa por ser num contexto de abertura do setor petrolífero no Brasil, iniciado em 6/8/97 com a edição e implementação da lei 9.478/97. Neste novo cenário de abertura e acirrada competitividade, a empresa vem empreendendo ações quanto a sua preparação, não só com vistas a manutenção de seu crescimento, como também solidificá-la e tornar-se uma companhia de energia. A atuação da Petrobras, hoje, ocorre de forma integrada e especializada nos segmentos relacionados à indústria de óleo, gás e energia, explorando as seguintes atividades: exploração e produção, refino, geração de energia elétrica, comercialização, transporte, petroquímica e distribuição de derivados.

Os relatórios econômico-financeiros da Petrobras relativos às atividades desenvolvidas em 2001 evidenciam os seguintes números: receita líquida de cerca de $\mathrm{R} \$ 57.512$ milhões, EBITDA de $\mathrm{R} \$ 17.250$ milhões e lucro líquido de R \$ 9.867 milhões ou R \$ 9,08 por ação. Seu ativo total é de R 75.159 milhões, sendo $\mathrm{R} \$ 29.538$ milhões o ativo permanente e um patrimônio líquido de R 28.967 milhões. Seu capital humano - talentos - é formado por 38.481 colaboradores, dos quais 32.809 na holding e os 5.674 restantes distribuídos pelas subsidiárias.

\section{Universidade Corporativa}

Nos dias de hoje, toma corpo e cada vez mais se materializa a idéia/ conceito de Universidade Corporativa (UC). EBOLI (1999) conceitua UC como “...um sistema eficaz de desenvolvimento de competências e talentos huma- 
nos nas empresas; não sendo uma ameaça às universidades tradicionais, nem significando esvaziamento no papel das mesmas".

Com o propósito de cada vez mais solidificar a sua filosofia de busca constante no aprimoramento do seu corpo técnico, no ano de 2000, com a implantação do novo modelo de gestão, foi criada a Universidade Corporativa, a qual tem desenvolvido programas com ênfase em EAD. Atualmente a companhia conta com 39 salas de videoconferência, espalhadas por todas as áreas importantes onde atua, o que abrange praticamente quase todo o território nacional.

A Petrobras, de longa data investe na formação de seus técnicos na área de prospecção, beneficiamento, distribuição e comercialização de petróleo, derivados e administrativos em geral, por meio da atuação de um órgão específico, hoje denominado Universidade Corporativa.

\section{Antecedentes do projeto}

Com as crescentes ondas de desregulamentação de mercado em curso no mundo, e em específico no Brasil, com a conseqüente quebra de monopólio de muitas atividades até então exclusivas do Estado, como a exploração do petróleo (1954 a 1997), mudanças significativas e profundas ocorrem na gestão das empresas envolvidas. Com a Petrobras não poderia ser diferente.

A Petrobras, diante desse cenário, passou a atuar dentro de um contexto de competitividade. Já não basta ser a melhor nos aspectos técnicos de extração, produção e distribuição. É necessária uma visão sistêmica na qual as decisões são tomadas com base em parâmetros econômicos. Preliminarmente, a FIPECAFI atuou na Petrobras como consultora no desenvolvimento de modelos de avaliação de desempenho econômico-financeiro para os segmentos de E\&P e de Abastecimento.

A caracterização desse cenário acarretou a identificação de uma demanda interna por conhecimentos em uma área específica - Controladoria - que contribuísse fornecendo as bases necessárias para o processo de capacitação dos funcionários envolvidos.

A FIPECAFI/FEA/USP, por meio de seu Programa de Educação Continuada, oferece na modalidade presencial o curso MBA Controller aberto ao público em geral, com ampla aceitação e reconhecimento no mercado. A relação 
FIPECAFI - Petrobras assumiu a configuração de parceira no desenvolvimento e implantação do projeto que atende a demanda identificada e as suas especificidades. Ao prover um programa de educação em nível de pós-graduação em parceria com a Universidade de São Paulo, por meio da FIPECAFI, a Petrobras corrobora EBOLI (1999) para quem

\begin{abstract}
...as experiências mais bem-sucedidas de Universidades Corporativas são aquelas que realizaram parcerias com algumas universidades que têm a competência para agregar valor a estes programas corporativos, contribuindo assim para que as empresas realizem com mais competências e resultado o processo de gestão dos conhecimentos considerados críticos para o sucesso do negócio.
\end{abstract}

Um dos aspectos desafiadores neste projeto foi a dispersão de domicílio dos alunos potenciais, já que para um curso totalmente presencial, os deslocamentos acarretariam custos com transportes, hospedagem e alimentação que, em função da duração do curso e do calendário o inviabilizaria do ponto de vista econômico. A solução encontrada, viabilizadora do Programa MBA Controller com a Petrobras, foi a de desenhar um curso cujo modelo é o semipresencial.

\title{
Proposição de um modelo semi-presencial: desenho e implementação
}

Em contraposição ao meio convencional de aulas presenciais, há a modalidade Ensino a Distância (EAD). A idéia não é nova, veja-se por exemplo o quase secular - ou será secular? - ensino por correspondência.

O EAD assume novos contornos, sendo suas potencialidades alavancadas de maneira fantástica pelo avanço da Tecnologia de Informação (TI). Os instrumentos disponibilizados mais em uso/discussão são a internet e a videoconferência (VC). No primeiro, as aulas podem ser síncronas (com a presença do instrutor/professor/tutor) ou assíncronas, sem a interação on line do professor/instrutor/tutor. Por VC, o usual tem sido as sessões síncronas. 
Igualmente importante é o comprometimento dos mentores - por nós denominados de patronos - dos programas, não só na sua formatação, como no acompanhamento. São pontos importantes na reflexão que será empreendida, além destes, os seguintes aspectos quanto ao desenho e implementação do projeto (curso), a operacionalização, práticas didáticas empregadas no processo ensino-aprendizagem num contexto semi-presencial, o comportamento/envolvimento dos docentes/discentes/coordenação e, principalmente, os meios de comunicação utilizados, com destaque especial a videoconferência e outras soluções de apoio, por exemplo, internet e intranet. Por fim, o referencial teórico existente sobre o assunto, as experiências - com os acertos e erros - vivenciados e descritos no caso abordado, constituem-se em rico material quanto a formar um corpo de conhecimentos, norteadores no design e implementação de cursos futuros, com qualidade para todos os envolvidos.

\section{O curso}

No âmbito dos cursos oferecidos pela FIPECAFI/FEA/USP, a inovação e pioneirismo está em ser o primeiro a utilizar novas mídias de interação voltadas a instrumentalizar o EAD, no caso a videoconferência (VC).

O curso compreendeu 25 disciplinas distribuídas ao longo de três semestres. As aulas ocorreram no período de agosto de 1998 a dezembro 1999, num total de 400 horas-aula.

Considerando a dispersão geográfica dos participantes, num país da dimensão continental como o Brasil, a magnitude da Petrobras e o fato de que nem todos os participantes se conheciam, além de aspectos pedagógicos, houve por bem se definir por um modelo de curso semi-presencial.

Nesse modelo, parte das aulas foram in loco, nas instalações da FIPECAFI/ FEA/USP em São Paulo e as demais por VC. As aulas presenciais ocorreram sempre no início e fim de cada semestre letivo, ou seja, duas semanas por semestre.

O curso todo perfez 400 horas-aula, das quais $40 \%$, ou seja, 160 horasaula foram ministradas por VC. A distribuição ao longo dos três semestres letivos foi: $1 .^{\circ}$ semestre 80 aulas presenciais (P) e 60 por videoconferência (VC), no $2 .^{\circ}$ semestre $80 \mathrm{P}$ e $68 \mathrm{VC}$ e no último semestre $80 \mathrm{P}$ e 32 por VC. A adoção de um modelo semi-presencial atendeu ao objetivo de, entre outros, promover uma interação pessoal entre os participantes dada as características de dispersão de domicílio/trabalho em que muitos, apesar de atuarem em áreas com afinidades não se conheciam. 
As aulas presenciais foram ministradas de segunda a sexta-feira com uma carga horária diária de 8 horas. Por VC as sessões eram de 4 horas, sempre às segundas-feiras das $8 \mathrm{~h} 30$ às $12 \mathrm{~h} 30$.

\section{As salas de aulas virtuais}

O caráter pioneiro do curso é o de ser um modelo semi-presencial em relação ao conjunto dos oferecidos no Programa de Educação Continuada da FIPECAFI/FEA/USP. A inovação não é só por ser multiponto, mas, sim, envolvendo originariamente 17 localidades, distribuídas conforme tabela a seguir:

\begin{tabular}{|l|l|c|c|}
\hline \multicolumn{3}{|c|}{$\begin{array}{c}\text { LOCAIS RECEPTORES DA TRANSMISSÃO DAS AULAS DO } \\
\text { MBA - CONTROLLER }\end{array}$} \\
\hline \multicolumn{1}{|c|}{ Localidade } & \multicolumn{1}{|c|}{ Órgão } & $\begin{array}{c}\text { Qtd } \\
\text { Alunos }\end{array}$ & $\begin{array}{c}\text { Aula } \\
\text { P/VC }\end{array}$ \\
\hline 1. Rio de Janeiro & ABAST/SEDE & 7 & VC \\
2. Rio de Janeiro & E\&P/SEDE & 7 & VC \\
3. Macaé & E\&P/BC & 3 & VC \\
4. Manaus & REMAN & 1 & VC \\
5. Araucária & REPAR & 1 & VC \\
6. São Paulo & GEASP & 2 & P \\
7. Capuava & RECAP & 1 & VC \\
8. Paulínia & REPLAN & 1 & VC \\
9. São José dos Campos & REVAP & 1 & VC \\
10. São Francisco do Sul & DTSUL & 1 & VC \\
11. São Mateus & E\&P/ES & 1 & VC \\
12. Itajaí & E\&P/SUL & 1 & VC \\
13. Mataripe & RLAM & 1 & VC \\
14. Salvador & E\&P/BA & 3 & VC \\
15. Natal & E\&P/RNCE & 3 & VC \\
16. Aracajú & E\&P/SEAL & 2 & VC \\
17. Belém & E\&P/AM & 1 & VC \\
Total de pontos $\rightarrow>$ alunos & & & \\
\hline
\end{tabular}


Dos 37 alunos iniciantes, 35 concluíram o curso. A desistência de dois alunos reduziu o número de salas envolvidas para 16, deixando de fazer parte da rede a sala São José dos Campos/REVAP.

As aulas foram geradas a partir da sala de videoconferência especial, localizada na unidade administrativa GEASP em São Paulo para um determinado conjunto de salas. Na GEASP/SP dois alunos assistiram o curso "ao vivo", o que explica o porquê na tabela estarem dois alunos classificados como presencial (P). O equipamento utilizado é o PictureTel multiponto. A retransmissão para as demais salas envolvidas ocorre a partir de um multiplexador localizado em uma unidade no Rio de Janeiro. Os recursos disponíveis foram: câmera de vídeo, microfones, caixas acústicas, televisores, videocassetes, microcomputadores, transformador de sinal de vídeo de microcomputador.

Para que o professor tivesse condição de se preocupar só com aula, sabidamente mais desgastante que as ministradas em ambiente convencional, a GEASP/SP disponibilizava um funcionário responsável pelos aspectos técnico-operacionais de utilização do equipamento. Toda a rotina pré-aula tem a semelhança de uma transmissão ao vivo de um evento na TV. O responsável pelo apoio tem que ter uma ótima interação com o professor, inclusive combinando antecipadamente alguns passos. A parte de logística, quanto a distribuição de material para os alunos, ficou a cargo da área de apoio na unidade GEASP/SP.

Para facilitar a interação aluno/professor/coordenação, foi desenvolvida uma página na internet. No entanto, face a problemas técnicos dentro da empresa, este importante instrumento de apoio não funcionou adequadamente. Como no curso em questão os alunos estão realmente distantes do professor (ao menos geograficamente), torna-se imprescindível a construção de ambiente (virtual) para os assuntos comuns da disciplina ou curso. Desta forma, a solução ideal é a construção de website que contenha detalhes sobre o curso, as disciplinas, os professores, área para troca de idéias entre alunos, acesso aos materiais didáticos, entrega de trabalhos, exercícios, casos, respostas, entre outras coisas.

Assim, é imprescindível reiterar que a concepção e desenvolvimento do curso com tecnologia de educação a distância envolvem, como já foi dito, um conjunto de preocupações bem distintas daquelas reconhecidas na forma tradicional. É importante possuir uma equipe técnica especializada, capaz de lidar com os detalhes técnicos continuamente. Há o envolvimento da equipe da instituição de ensino, de pessoal com características distintas (artes, design, programação) dos profissionais até então atuantes (aspectos comportamentais). 
Não basta "montar" a estrutura do curso e das disciplinas e alijar-se do processo. No caso, o apoio utilizando a internet exige a manutenção do website, com todos os recursos atualizados e interessantes para os usuários, fator tão relevante quanto a sua própria criação. A tecnologia é muito volátil e a obsolescência nesta área é muito intensa, o que reforça a necessidade das manutenções.

\section{A mídia videoconferência: seu papel na viabilização do modelo semi- presencial}

CRUZ e BARCIA (2000) observam que quanto às tecnologias existentes e viáveis de serem utilizadas no ensino a distância “...a videoconferência é a que mais se aproxima de uma situação convencional da sala de aula, já que, ao contrário da teleconferência, possibilita a conversa em duas vias, permitindo que o processo de ensino/aprendizagem ocorra em tempo real (on line) e possa ser interativo, entre pessoas que podem se ver e ouvir simultaneamente".

Videoconferência é um sistema interativo de comunicação em áudio e vídeo, que permite a interatividade e a disseminação das informações bem como promover a troca destas - a um largo número de pontos geograficamente dispersos. É uma tecnologia que, conforme CRUZ e BARCIA (2000) “...permite que grupos distantes, situados em dois ou mais lugares geograficamente diferentes, comuniquem-se "face a face", através de sinais de áudio e vídeo, recriando, à distância, as condições de um encontro entre pessoas."

A utilização da mídia videoconferência como elemento viabilizador de cursos - no todo ou em parte - é sem dúvida uma alternativa no processo de educação continuada dos colaboradores das empresas. Tem um forte apelo de economia de investimentos em educação, notadamente naquelas organizações que, à semelhança da Petrobras, têm seus locus operacionais dispersos e às vezes de difícil acesso.

CRUZ e MORAIS apud CRUZ e BARCIA, com relação à utilização da mídia videoconferência na educação, listam as seguintes vantagens e desvantagens: 
Este novo ambiente de sala de aula virtual é extremamente motivador e ao mesmo tempo desafiador aos atores envolvidos: ao professor, no que diz respeito à preparação da aula, condução com dinamismo, avaliação dos alunos e aos alunos quanto à apreensão do conteúdo, como sanar as dúvidas.

\begin{tabular}{|c|c|}
\hline VANTAGENS & DESVANTAGENS \\
\hline $\begin{array}{l}\text { 1. permite uma transição mais gradu- } \\
\text { al dos métodos presenciais; } \\
\text { 2. permite espaço colaborativo para } \\
\text { socialização e aprendizado } \\
\text { colaborativo em grupo; } \\
\text { 3. possibilita escolher e planejar cur- } \\
\text { sos interativos para classes peque- } \\
\text { nas ou menos interativo para gran- } \\
\text { des audiências; } \\
\text { 4. pode-se escolher os meios de trans- } \\
\text { missão conforme possibilidade, } \\
\text { disponibilidade e demanda. }\end{array}$ & $\begin{array}{l}\text { 1. a baixa qualidade de som e imagem } \\
\text { 2. dificuldade de se adaptar a sala de } \\
\text { videoconferência à situação didá- } \\
\text { tica; } \\
\text { 3. os altos custos de implementação, } \\
\text { instalação e manutenção compara- } \\
\text { dos com um baixo uso na fase ini- } \\
\text { cial; } \\
\text { 4. altos custos de transmissão das li- } \\
\text { nhas telefônicas; } \\
\text { 5. por desconhecimento, não utilizar } \\
\text { todo o potencial didático do meio, } \\
\text { reduzindo-o a mera reprodução de } \\
\text { palestras, com pouca interação en- } \\
\text { tre os participantes. }\end{array}$ \\
\hline
\end{tabular}

\section{Reflexões}

Aula por videoconferência: treinamento, oportunidades, desafios e limitações

A Petrobras é pioneira no uso tecnologia em VC e desenvolveu uma sólida cultura enquanto usuária para reuniões, comunicações, palestras e treinamentos in company. Diante disso, houve por bem contar com o apoio de seus profissionais no treinamento dos professores. Inicialmente, uma visão geral sobre o que é VC, porém, com ênfase na sua utilização como meio de ensino. Na seqüência, os demais pontos foram: preparação do material, ritmo 
das aulas, interação com os alunos, postura, traje adequado. Quanto aos aspectos mais técnicos relacionados a equipamentos, os professores puderam se familiarizar com os equipamentos disponíveis para uma aula por VC. Além do PictureTel, o professor conta com uma câmera de documentos, microcomputador e os convencionais flip chart e quadro branco.

O transcorrer do curso evidenciou a existência de outras preocupações tanto para o professor quanto para os alunos envolvidos com esse meio: iluminação, foco, intensidade e volume da fala, coloração de roupas, recursos de áudio, operação de recursos de videoconferência etc. Tais preocupações são diferentes das existentes em ambiente convencional de sala de aula. Há também limitações: não se pode ver e ouvir todos ao mesmo tempo.

Em geral os alunos recebem o sinal do professor, que pode "passar a palavra" para uma outra sala de videoconferência, quando então, esta última passa a enviar seu sinal para todas as demais. No caso deste curso, especificamente, a sala onde se encontrava o professor possuía dois aparelhos de vídeo, permitindo a ele ter sua imagem e som (a semelhança das demais salas), bem como a imagem da última sala com a qual interagiu. De um modo geral, não foram percebidas pelos professores diferenças significativas quanto ao aproveitamento dos estudos nesta modalidade em relação à forma tradicional. A comparação é permitida pelo fato de que, como já afirmado, a disciplina é normalmente oferecida em cursos presenciais. Porém, existiram diferenças significativas na oferta de conteúdo (professor) e na forma de aprendizado (aluno).

Aspectos relevantes sobre as práticas didáticas

Os cursos do Programa de Educação Continuada oferecidos pela FIPECAFI/ FEA/USP, como não poderia deixar de ser, destinam-se a um público composto de alunos adultos. Nota-se que este público adulto, no caso, participantes de cursos de estudos complementares (pós-graduação), tem um natural interesse no "aprender". O fator "vontade" se faz presente, embora essa não seja a constatação sobre a totalidade dos alunos. No caso de haver a presença sincera da vontade em aprender, os meios adotados passam a ser "meios" e os interessados buscam transpor eventuais barreiras que a "experiência" possa eventualmente aumentar. 
Quando se relacionam idades maiores e tecnologias, algumas pessoas afirmam, de forma leviana, que não se obtém um bom resultado. No caso do "aprender", as tecnologias envolvidas passam a ser facilmente transpostas. Se o aluno não possuir os requisitos mínimos de conhecimento sobre as tecnologias envolvidas, haverá estímulo para a transposição desta dificuldade.

Os professores envolvidos com disciplinas ministradas por VC passam por um processo de quebra de paradigma pedagógico. CARBONELL (2002, p. 57) observa que "integrar e dominar as novas tecnologias da informação exige uma relação mais interativa entre os professores e os alunos para poder trocar e compartilhar de maneira mais fluida e permanente o acesso, a seleção, a associação e a crítica do conhecimento."

Dessa forma, os professores participantes do programa procederam a uma revisão de seus materiais de apoio e metodologia habitualmente utilizada no processo ensino/aprendizagem. Isso exigiu não só a adequação ao formato dentro dos padrões exigidos para uma aula por VC, como também o pensar de novas práticas didáticas.

No entanto, essa pequena travessia não foi fácil. Neste caso, o esforço para o desenvolvimento e produção do material foi sensível, mesmo considerando que as disciplinas são usualmente oferecidas em cursos tradicionais de MBA Controller. A motivação do professor de investir seu tempo na adequação da sua disciplina às necessidades e características do EAD é imperativa para a qualidade do programa e muitas vezes se contrapõe a dúvidas quanto aos diretos autorais e de imagem, uma vez que as aulas por VC são gravadas e podem ser reproduzidas.

A proposição de leituras prévias e desenvolvimento prévio de exercícios e estudos de casos foi uma estratégia para a organização das aulas. Esta alternativa permitiu o uso comum da videoconferência para sanar dúvidas e estabelecer discussões acerca dos temas com os alunos.

O que se pode apreender nesta experiência é que as práticas didáticas especificamente voltadas para o uso da mídia VC em um curso EAD foram praticamente inexistentes. Há um imenso caminho a percorrer. Pesquisas têm que ser desenvolvidas e muito rapidamente. Há um profundo hiato entre o arcabouço das facilidades tecnológicas e o repertório de metodologias para o ensino via EAD. Os professores procuraram seguir os ensinamentos/dicas do treinamento ministrado pela Petrobras. Dos muitos tópicos tratados, merece destaque aqueles relativos às abordagens pedagógicas a serem adotadas na condução das aulas, bem como a maneira adequada de agir diante das câmeras e os cuidados a serem tomados quando da interação com os alunos, visto que não estão dispersos em $n$ salas virtuais, exigindo que as intervenções ocorram 
de forma coordenada, evitando que dois ou mais alunos falem ao mesmo tempo. Com relação ao uso dos instrumentos auxiliares - microcomputador, câmera de documentos, quadro branco, flip chart - colocados a disposição, as dicas/ensinamentos foram no sentido de que eles podem ser utilizados para tornar a aula mais dinâmica, mais interativa. Por exemplo, um professor pode estar utilizando o aplicativo Power Point e, em determinado momento, o flip chart ou quadro branco para detalhar uma explicação, ou encaminhar/desenvolver junto com os alunos a solução de uma questão.

Por fim, pôde ser verificada a viabilidade de ministrar disciplinas de cunho estritamente quantitativas, como métodos quantitativos e cálculo financeiro, que tiveram ótima aceitação e aproveitamento por parte dos alunos. Os professores destas matérias optaram por incluir no material previamente distribuído exercícios resolvidos, além daqueles a resolver. Assim fazendo, percebemos que essa atitude criou uma confiança no aluno e por consequiência o induziu a maior participação.

\section{Considerações finais}

Estamos passando por um período de enorme valorização do saber. É antes de tudo um momento rico e muito desafiador para todos os envolvidos. Nem por isso, menos oportuno. Há que se construir novos paradigmas no processo ensino-aprendizagem tendo em vista a EAD, em específico no nosso caso, mediado pela mídia videoconferência.

A construção desse novo paradigma passa pelo desenvolvimento de modelos pedagógicos, com forte ênfase na dinâmica da aula, na elaboração de material, na motivação, acompanhamento e avaliação dos alunos.

A atuação do professor no contexto da EAD por videoconferência exigirá cada vez mais a formação de equipes multidisciplinares de apoio à elaboração e desenvolvimento da aula. Não haverá espaço para improvisar. O aluno deverá ser cada vez mais ético, disciplinado e pesquisador.

Aspectos de legislação serão necessários para garantir o direito autoral e de imagem do professor e/ou equipe envolvida no desenvolvimento do material e da aula, visto que esta poderá ser gravada.

Estamos no inicio de uma caminhada. Muitos são os desafios. Cabe a nós convertê-los em oportunidades diferenciadoras de nossa atuação no ensino. 


\section{REFERÊNCIAS}

CARBONELL, J. A aventura de inovar: a mudança na escola. Porto Alegre: Artmed, 2002.

CATELLI, A. (Coord.). Controladoria: uma abordagem da gestão econômica-Gecon. São Paulo: Atlas, 2001.

CRUZ, D. M.; BARCIA, R. M. Educação a distância por videoconferência. Tecnologia Educacional, ano 28, n. 150/151, p. 3-10, jul./dez. 2000.

EBOLI, M. et al. (Coord.). Coletânea universidades corporativas - Educação para as empresas do século XXI. São Paulo: A. Schmukler, 1999.

HARE, C. New technologies and the education of information professionals. Salamanca: Universidad de Salamanca, 2000. Disponível em: <http://teleeduca.usal.es/ teoriaeducacion/articulosnuneroactual/n2_art_hare.htm> Acesso em: 16 mar. 2001.

LUCCHESI, C. F. Petróleo in Estudos Avançados - Universidade de São Paulo. Institutos de Estudos Avançados, v. 12, n. 33, p. 17-40, maio/ago. 1998.

Texto recebido em 20 jan. 2003 Texto aprovado em 20 de mar. 2003 